Vol. 14 , no. 1 , June 2020 , pp. 1-5

10.2478/host-2020-0001

\title{
Introduction: Standards in the History of Contemporary Science
}

\author{
Javier Ordóńez and Antonio Sánchez \\ Autonomous University of Madrid \\ javier.ordonnez@uam.es / antonio.sanchezm@uam.es
}

Standards have played a major role in the history and development of science, to such a degree that an essential dimension of the history of science and technology can be reconstructed at both epistemological and institutional levels through the study of the formulation and refinement of standards and the process of standardization. ${ }^{1}$ The exacting and systematic definition of standards is a solid indicator of the robustness of scientific fields and disciplines. By following the paths of their successive definitions, one can even reveal the history of essential epistemic values and virtues, such as precision or simplicity. Standards are used to refine concepts and to build new experimental practices that in turn foster the development of more robust standards

\footnotetext{
${ }^{1}$ See Stefan Timmermans and Steven Epstein, "A World of Standards but not a Standard World: Toward a Sociology of Standards and Standardization," Annual Review of Sociology 36 (2010): 69-89; and James Sumner and Graeme J. N. Gooday, "Introduction: Does Standardization Make Things Standard?" in "By Whose Standards? Standardization, Stability and Uniformity in the History of Information and Electrical Technologies," eds. James Sumner and Graeme J. N. Gooday, special issue, History of Technology, Series editor Ian Inkster, 28 (2008): 1-14.
}

\section{(C) 2020 Javier Ordóñez and Antonio Sánchez .}

This is an open access article licensed under the Creative Commons Attribution-NonCommercial-NoDerivs License (https://creativecommons.org/licenses/by-nc-nd/4.0/). 
- not arbitrary - in a virtuous circle. ${ }^{2}$

Standards in the physical sciences such as the units of measurement helped to inspire the elaboration of standards in related disciplines. ${ }^{3}$ They were used as a paradigm to define standards in the biomedical and social sciences. ${ }^{4}$ Even mathematics creates its own notion of standards in relation to disputes about the nature of and elegance in the organization of knowledge. More experimental disciplines used standards to build epistemic bridges between the laboratory and industry. The advantages of standardization could be regarded by societies as the spread of the scientific efficacy and technological sophistication to the social organization. In the last two centuries, people concerned with the organization of knowledge did not seem to consider that it could be done without counting on institutional frameworks devoted to managing the standardization processes.

Despite the centrality of standards in shaping our knowledge practices, ${ }^{5}$ the epistemological and institutional issues pertaining to the processes of formulating and refining standards have not attracted much attention. Part of the literature of science and technology studies has considered standards as tools to homogenize, to bureaucratically manage knowledge and societies, and to create "objectivity conditions," standards have not received equal interest and treatment. How do standards and the institutions devoted to their formulation contribute to the production of knowledge? Are they mere convenient tools? Do they shape a form of scientific objectivity? What is the epistemological contribution of standards in science? Can we speak of the practical, even artisanal, dimension of standardization in science? This special issue will try to answer some of these questions

\footnotetext{
${ }^{2}$ Joan H. Fujimura, "Standardizing Practices: A Socio-History of Experimental Systems in Classical Genetic and Virological Cancer Research, ca. 1920-1978," History and Philosophy of the Life Sciences 18 (1996): 3-54.

${ }^{3}$ There is an extensive bibliography on this subject. Among the most recent works, see Martha Lampland and Susan Leigh Star, eds., Standards and Their Stories: How Quantifying, Classifying, and Formalization Practices Shape Everyday Life (Ithaca, NY: Cornell University Press, 2009); Hasok Chang, Inventing Temperature. Measurement and Scientific Progress (Oxford: Oxford University Press, 2004).

${ }^{4}$ See Robert G. W. Kirk, "Standardization through Mechanization: Germ-Free Life and the Engineering of the Ideal Laboratory Animal," Technology and Culture 53, no.1 (2012): 61-93; Karen A. Rader, Making Mice: Standardizing Animals for American Biomedical Research, 1900-1955 (Princeton, NJ: Princeton University Press, 2004); Stefan Timmermans and Marc Berg, The Gold Standard: The Challenge of Evidence-Based Medicine and Standardization in Health Care (Philadelphia, PA: Temple Univ. Press, 2003); and Eviatar Zerubavel, "The standardization of time: a sociohistorical perspective," American Journal of Sociology 88 (1982): 1-23.

${ }^{5}$ Lawrence Busch, Standards. Recipes for reality (Cambridge, MA: The MIT Press, 2013). In this book, Bush considers standards as invisible yet ubiquitous means of ordering everyday reality and organizing our experience. They order and normalize people's lives. See also Nils Brunsson and Bengt Jacobsson, eds., A World of Standards (Oxford: Oxford University Press, 2000).

${ }^{6}$ Theodore Porter, Trust in Numbers: The Pursuit of Objectivity in Science and Public Life (Princeton, NJ: Princeton University Press, 1995).
} 
from different areas of knowledge such as astrophysics, mathematics, biology and ecology by analysing case studies spanning the last two centuries.

This special issue gathers together some of the results of the research project "Material cultures, epistemic cultures: Standards, cognitive processes and knowledge" developed at the Universidad Autónoma de Madrid (Spain) between 2014 and 2018. This project was composed almost entirely of philosophers and historians of science. The four papers in this issue correspond to the group of historians of science. The aim of the issue is to offer four concrete cases in which the processes of standardisation play a decisive role in the production of scientific knowledge and stimulate debate around standards and science.

Despite their different approaches to the subject of standards, these articles are brought together in this special issue because they all overlap on materialities and epistemological approaches considering the place of standards in science. As such, they are addressed both to the public interested in the general debate on standards, and to the public belonging to the sub-disciplines of the four respective authors. The former will find new and stimulating case studies. The latter will find new methodological and interpretative tools with which to analyse their field of study.

On the following pages, the reader will find four articles written by renowned specialists on the relationship between standardisation processes and scientific knowledge in the contemporary era, the nineteenth and the twentieth centuries. The first article, by the historian of science Javier Ordónez, explores standardisation processes in the emerging field of astrophysics - the new astronomy - based on the fruitful interaction between artisans and scientists, between practical and theoretical individuals. Ordóńez focuses on two key moments in the development of astrophysics; the processes of standardization of the manufacture of the glass with which the lenses of refracting telescopes were made, and the construction of instruments that improved the ways of classifying the magnitude of stars. One of the most notable aspects of this article is the relationship that is established between the processes of standardization of astrophysical knowledge and that of artisanal culture. By way of example, the case of Joseph Ritter von Fraunhofer (1787-1826) is illustrative of artisan knowledge that helps us to understand how complex processes of standardization in science were configured in the nineteenth century.

The second article, written by the historian and philosopher of mathematics José Ferreirós, examines the mathematical roots of the standardization processes - especially of weights and measures - involving the life of mathematician and astronomer Johann Carl Friedrich Gauss in the German state of Hanover during the first half of the nineteenth century. Ferreirós' article not only offers a new case study on science and standards in the area of the history of science and technology, but also suggests investigating the close relationship that seems to exist between some of the most important mathematical proposals of the nineteenth century 
and the standardization processes, both inside and outside the world of mathematics. The originality of this article lies in showing the connections that exist between apparently separate fields, those of standardization initiatives, regarding weights and measures, error control, high precision instruments, and mathematical thinking, which emphasizes the inescapable technical side of maths. Gauss' works are a model example of these connections, and his reflections on foundations and rigour draw connections with his more technical efforts.

The article by the historian of biology María Jesús Santesmases reconstructs and analyses the sophisticated technical mechanisms that allowed the visual representation of chromosomes to be put into circulation and standardized from the mid-twentieth century onwards. Santesmases starts from the deep conviction that the genetic knowledge of our days owes much to what she calls the visual epistemology of genetics. In other words, according to Santesmases, genetics owes a great debt to the techniques of chromosome visualization. Standard images of human chromosomes began to circulate after a meeting of cytogeneticists in 1962. The images produced, after a long history of schemas and idealized chromosome drawings and photomicrographs, participated in the emergence of a specific and enduring way of representing the miniscule parts of cells where division begins, and accounted for both the forms and function of chromosomes at the origins of medical genetics.

In the last article, the historian of science Nuria Valverde analyses from a more philosophical perspective the logics of standard setting in artificial environments of preservation and cohabitation in the mid-twentieth century. More specifically, Valverde analyses two cases. In one case she studies the emergence of sound recording instruments that enable the definition of standards for the preservation of endangered birds in urban environments. In the other, she performs a critical study of the creation of closed artificial environments - such as the so-called iron lungs for polio patients - as another form of life preservation. The main point of this article is that the inevitable implementation of standards in preservation contexts may lead to the invisibility of new modes of existence, or to confusion about the status of what emerges in that space. This is either because what is intended to be preserved has already changed - the parameters that identify an entity or category are no longer useful - or because the very act of seeking to preserve it by adjusting its behaviour to variables made possible by a technological environment transforms it - making the entity in question dependent on the preservation context. 


\section{Acknowledgements}

The authors wish to express here their sincere gratitude to Jesús Vega for the support he has given us in the preparation of this special issue. They also express their thanks to Billy Falvey for his help with the English version of these pages.

\section{Competing interests}

The authors have declared that no competing interests exist.

\section{Funding}

This work has been supported by the projects: "Material cultures, epistemic cultures. Standards, cognitive processes and knowledge" (State Plan ICyT-i, FFI2013-45659-R), directed by Jesús Vega Encabo (UAM, Madrid). 